\title{
Computer Aided Investigation towards the Wind Power Generation Potentials of Guangzhou
}

\author{
Gang Yang, Yongxian Du \& Ming Chen \\ Institute of Solar Energy System \\ Key Laboratory of Guangdong Educational Department \\ School of Physics and Engineering \\ Sun Yat-sen University \\ Mingde Garden 9-322, University City, Guangzhou 510006, China \\ Tel: 86-20-3933-0895 E-mail:ee04yg@sysu.edu.cn
}

The research is financed by the Chinese national 863 plan projects. No. 2006 AA05Z409

\begin{abstract}
Wind power generation potential of Guangzhou has been analyzed based on the wind speed data collected in the recent 30 years. In order to make the results more accurate, the Weibull distribution function is introduced and the two parameters can be identified by CAD method together with local weather data available. By referring to the power characteristics of the wind turbines, the monthly and yearly operating probabilities and the output power under different heights are analyzed. Given by the above data and the power generation cost, it is proved that although the wind power resources in Guangzhou is not very ideal, it can also be utilized to generate power.
\end{abstract}

Keywords: Weibull distribution function, CAD, Height, Power characteristic, Power generation cost

\section{Introduction}

Guangzhou is one of China's leading economic cities and a massive manufacturing center. Along with the rapid development of economy, the demand of energy, especially electricity, is also growing at a fast speed. As the conventional energy generation will inevitably cause the emissions of poisonous gas and the greenhouse effect, it is necessary to ensure rational utilization of renewable energy to help protect the environment. Wind power generation, as an important part of the renewable energy, is put emphasis on in the recent years all over the world. However, the study towards the wind power generation potential of Guangzhou is very limited. This paper aims to analyze the wind power generation potentials of Guangzhou by using the collected weather data and wind turbine characteristics.

\section{Models for wind power potential analysis}

\subsection{Weibull distribution function}

The wind frequency distribution is used to determine the probability under which one wind speed occurs. Among the many different ways used to build such a distribution, the Weibull distribution function, as expressed by Eq. (1), is proved to be a simple but efficient way to fit the real wind speed distribution. The two adjustable parameters, $k$ and $c$ can be identified by using the average wind speed $\bar{v}$ and the maximum wind speed $v_{\max }$.

$$
\begin{gathered}
f(v)=\frac{k}{c}\left(\frac{v}{c}\right)^{k-1} \exp \left[-\frac{v}{c}\right]^{k}(k>0, v>0, c>1) \\
c=\frac{\bar{v}}{\Gamma(1+1 / k)}
\end{gathered}
$$

where $f(v)$ is the Weibull distribution probability of wind speed, $c$ is the Weibull scale parameter and $k$ is the dimensionless Weibull shape parameter.

The wind speed data is measured hourly and in a time segment $t$, the probability that the maximum wind speed $v_{\max }$ occurs is expressed by Eq. (3) and the result is expressed by Eq. (4). 


$$
\begin{gathered}
P\left(v \geq v_{\max }\right)=\exp \left[-\left(\frac{v_{\max }}{c}\right)^{k}\right]=\frac{1}{T} \\
\frac{v_{\text {max }}}{\bar{v}} \Gamma\left(1+\frac{1}{k}\right)=(\ln T)^{\frac{1}{k}}
\end{gathered}
$$

where $\Gamma(1+k)=\int_{0}^{\infty} x^{\frac{1}{k}} e^{-x} d x ; T=24 d v_{\max } ; d$ is the number of days per month.

The parameter $k$ can be calculated by the average wind speed $\bar{v}$ and the maximum wind speed $v_{\max }$ while the parameter $c$ can be determined by the Eq. (2). The Eq. (4) is a transcendental equation which can be calculated by using the computer-aided method, shown in the Figure 1.Eq. (4) can also be calculated by using the iterative method which is very complex for the hand-calculation. It can be seen from the Firgure 1 that the calculated parameter $k$ is exact until the $3^{\text {rd }}$ decimal place.

\subsection{Wind speed adjustment}

Wind speed near to the ground changes with height following the exponential law, thus the wind turbine hub height has a great influence on the amount of energy generated by the wind turbines. To calculate the output power of wind turbine, it is necessary to convert the measured wind speed to the wind speed at the wind turbine hub height. The most frequently used expression is the power law, expressed in Eq. (5).

$$
v=v_{0}\left(\frac{h}{h_{0}}\right)^{\alpha}
$$

Where $v$ is the wind speed at hub height $h$ compared to the sea level, $\mathrm{m} / \mathrm{s} ; v_{0}$ is the wind speed measured at the height $h_{0}$ compared to the sea level, $\mathrm{m} / \mathrm{s} ; \alpha$ is the ground surface friction coefficient, while it is about 0.107 at the sea surface, 0.146 at the weald and 0.25 at the town.

\subsection{Two meaningful wind speeds}

As the shape and scale parameter of Weibull distribution can be calculated, two meaningful wind speeds, the most probable wind speed $v_{M P}$ and the wind speed carrying maximum energy $v_{M a x E}$ can be obtained by the Eq. (6) (7).

$$
\begin{aligned}
& v_{M P}=c\left(\frac{k-1}{k}\right)^{\frac{1}{k}} \\
& v_{\text {MaxE }}=c\left(\frac{k+2}{k}\right)^{\frac{1}{k}}
\end{aligned}
$$

$v_{M P}$ denotes the most frequent wind speed for a given wind distribution function and $v_{\text {MaxE }}$ represents the wind speed that carries the maximum amount of wind energy.

\subsection{Power output characteristics of wind turbines}

According to the wind energy conversion theory and the Bates theory, the amount of power that one wind turbine actually obtains is summarized in the following Eq. (8):

$$
P=\frac{1}{2} C_{P} \rho S v^{3}
$$

where $\mathrm{P}$ is the amount of power that one wind turbine actually generates, $\mathrm{W} ; C_{P}$ is the wind power coefficient, with a limit value of $0.593 ; \rho$ is the air density, $\mathrm{kg} / \mathrm{m}^{3} ; S$ is the sweeping area of the wind wheel, $\mathrm{m}^{2} ; v$ is the wind speed, $\mathrm{m} / \mathrm{s}$

The Eq. (8) points out the relationship between wind speed and the power of wind turbines. The output power characteristic curve of wind turbines can be regarded as a 3rd power curve with constant parameters before reaching the maximum power point. This is also to say that $C_{P} \rho S$ can be regarded as a constant. After the wind turbine reaches its maximum output power, the sweeping area of the wind wheel changes as a result of the change of the blade angle. Thus the output power of wind turbine stops increasing and begin to remain steady or a slightly decreasing. The output characteristic of wind turbines can be expressed in the Eq. (9). 


$$
P(v)=\left\{\begin{array}{l}
0,\left(v \leq v_{c i}\right) \\
\mathcal{E} v^{3},\left(v_{c i} \leq v \leq v_{m}\right) \\
P_{m},\left(v_{m} \leq v \leq v_{c o}\right) \\
0,\left(v \geq v_{c o}\right)
\end{array}\right.
$$

where $\varepsilon=\frac{P_{R}}{v_{R}{ }^{3}}, v_{m}=\sqrt[3]{\frac{P_{m}}{\varepsilon}} ; v_{c i}$ is the cut-in wind speed, $\mathrm{m} / \mathrm{s} ; v_{c o}$ is the cut-out wind speed, $\mathrm{m} / \mathrm{s} ; \quad P_{R}$ is the rated electrical power of the wind turbine, W; $v_{R}$ is the rated wind speed, $\mathrm{m} / \mathrm{s} ; P_{m}$ is the maximum output electrical power, W; $v_{m}$ is the wind speed that corresponds to the maximum output power, $\mathrm{m} / \mathrm{s}$;

With the output power characteristic of the wind turbine and the Weibull distribution probability of wind speed, the energy that a wind turbine produces can be obtained by using the Eq. (10)

$$
\int_{v_{c i}}^{v_{c o}} P(v) f(v) d v
$$

\section{Analysis of Guangzhou's wind power generation potential}

\section{1 wind speed data of Guangzhou}

The wind speed data collected during the recent 30 years in each city can be found online at the "China Meteorological Data Sharing Service System". The weather station of Guangzhou locates at a height of 41 meters and it show that the average wind speed is $1.7 \mathrm{~m} / \mathrm{s}$ and the average maximum wind speed in the 30 years is $19.1 \mathrm{~m} / \mathrm{s}$. Figure 2 shows the above data colleted from that weather station in recent 30 years.

As shown in the Figure 2, the average wind speed in every month is among 1.5-2.0 m/s which is a low value and there is no significant differences of the average wind speed among different months. The average wind speed is low in June, July and September while the maximum wind speed in the three months is larger as a result of the frequent typhoons in Guangzhou. That is also why there are significant fluctuations of the maximum wind speed each year. In winter, to the contrary, the average wind speed is larger and the wind resources are relatively more abundant.

\subsection{Weibull probability density function}

The parameters of Weibull distribution can be obtained by the wind speed data available. The yearly wind probability density function of Guangzhou can be calculated by using the Eq. (1) (2) (3) (4) and the result is shown in Figure 3.

As is shown in Figure 3, the most probable wind speed occurs at the wind speed less than $1 \mathrm{~m} / \mathrm{s}$ which represents that the wind energy resources in Guangzhou is not an ideal resource for power generation. Using the equation (6) (7), the monthly Weibull function parameters are shown in Table 1.

\subsection{Operating probability of wind turbines}

The Weibull distribution density function gives the probability of the wind speed exceeding the value $u$ and between $u_{1}$ and $u_{2}$, given in the Eq. (11) (12).

$$
\begin{aligned}
& F(v)=1-\exp \left[-\left(\frac{v}{c}\right)^{k}\right] \quad P(v \geq u)=\exp \left[-\left(\frac{u}{c}\right)^{k}\right] \\
& P\left(u_{1} \leq v \leq u_{2}\right)=\exp \left[-\left(\frac{u_{1}}{c}\right)^{k}\right]-\exp \left[-\left(\frac{u_{2}}{c}\right)^{k}\right]
\end{aligned}
$$

Figure 4 shows the probabilities that the wind speed exceeding a certain value when the wind turbine hub height is $41 \mathrm{~m}$ compared to the sea level in Guangzhou. For most wind turbines, the cut-in wind speed is about $3 \mathrm{~m} / \mathrm{s}$ which signify that the wind turbine will not generate power unless the wind speed exceeds $3 \mathrm{~m} / \mathrm{s}$. It is usually that the cut-out wind speed is about $20-25 \mathrm{~m} / \mathrm{s}$, and the probability of wind speed exceeding $20 \mathrm{~m} / \mathrm{s}$ can be ignored. If $3 \mathrm{~m} / \mathrm{s}$ and $20 \mathrm{~m} / \mathrm{s}$ are regarded as the cut-in wind speed and cut-out wind speed, the operating probability of wind turbines in Guangzhou is 16.96\% which signifies that the wind turbine will work 1486 hours/ year. As wind speed is closely related to the wind turbine hub height, the operating probabilities of wind turbines under different heights can be obtained by the Eq. (5) and the $\alpha=0.146$. The operating probabilities of wind turbines under different heights in Guangzhou are shown in Figure 5.

As can be seen from Figure 5, the operating probabilities of wind turbines increase along with the increase of the wind turbine hub heights. In the wind turbine hub height of $200 \mathrm{~m}$, the operating probability rises from 0.1696 to 0.2490 
which signifies that the operating hours rises to 2182 hours/year.

\subsection{Analysis of energy generated by wind turbines}

One frequently used wind turbine FD2.5-300, produced in the Inner Mongolia, is used as an example to illustrate the power generation situation. The cut-in wind speed, the cut-out wind speed and the rated wind speed of the wind turbine FD2.5-300 is $3 \mathrm{~m} / \mathrm{s}, 20 \mathrm{~m} / \mathrm{s}$ and $8 \mathrm{~m} / \mathrm{s}$, respectively. The rated output power is $300 \mathrm{~W}$ and the maximum output power is $500 \mathrm{~W}$. By using the Eq. (9) (10), the energy generated by such a wind turbine per month in Guangzhou at the wind turbine hub height of $41 \mathrm{~m}$ is calculated, shown as in the Table 2.

From the Table 2, it is obvious that a yearly energy of $83.195 \mathrm{~kW} \cdot \mathrm{h}$ is generated by the wind turbine FD2.5-300 in Guangzhou; however, that number differs from the wind turbine hub heights. Figure 6 shows the energy generated by the wind turbine changes along with the wind turbine hub heights.

The wind turbine hub height has a great influence on the energy generated by the wind turbine, as shown in the Figure 6 . As a result of the increase of the wind turbine hub height, the wind speed rises and the operating probability also tends to be larger. When the height reaches $200 \mathrm{~m}$, the energy that generated by the wind turbine will be $161.382 \mathrm{~kW} \cdot \mathrm{h}$, nearly twice than that of at $41 \mathrm{~m}$.

\subsection{The estimation of the generation cost}

The cost of a wind turbine FD2.5-300 is about 2200 RMB and the typical service life of a wind turbine is 20 years, thus the wind power generation cost can be obtained by the following equation.

$$
m=\frac{M}{y W}
$$

Where $M$ is the total investment of a wind power system; $y$ is the lifetime of a wind turbine; $W$ is the energy generated by the wind turbine per year.

If the cost for batteries and further maintenances are not counted into the investment of a wind power system, the wind generation cost under different heights are analyzed and shown in Table 3.

The data of Table 3 shows that the height of wind turbine hub is a closely related factor to the energy generated by the wind turbine. At the height of $41 \mathrm{~m}$, the generation cost is $1.322 \mathrm{RMB} / \mathrm{kW} \cdot \mathrm{h}$. This figure falls to $0.68 \mathrm{RMB} / \mathrm{kW} \cdot \mathrm{h}$ at the height of 200 which is near to the cost of the commercial power.

\section{Conclusions}

This paper analyzed the wind power generation potential of Guangzhou. The Wibull distribution density function shows that the most probable wind speed of Guangzhou is lower than $3 \mathrm{~m} / \mathrm{s}$ and the wind energy resources in Guangzhou is not very ideal to generate power. The analysis of the operating probabilities proves that this figure remains between 0.17-0.25 which signifies that the operating hours per year is among 1500-2200 hours. The wind turbine hub height is proved to have a great influence on the energy generated by the wind turbine. The output power of wind turbines grows along with the rises of the height and the power generation cost decreases dramatically. The generation cost under a wind turbine hub height of $200 \mathrm{~m}$ is close to the cost of commercial power. Thus although the wind resources of Guangzhou is not very ideal, it can also be utilized. As wind power is proved to be a kind of green and clean resource and has no pollution that will be produced during the conventional power generation process, moreover, the wind energy in the offshore areas is better than the inland, thus the Guangzhou's wind energy also has a non-negligible utilization value.

\section{References}

Ai, Bin, Yang, Hongxing, Shen, Hui \& Liao, Xianbo. (2003). Optimum sizing of PV/wind hybrid system (1) CAD method. Acta Energiae Scolaris Sinica, 4, 540-547.

E.Kavak Akpinar \& S.Akpinar. (2005). An assessment on seasonal analysis of wind energy characteristics and wind turbine characteristics. Energy Conversion and Management, 46, 1848-1867.

Lu, Lin \& Yang, Hongxing. (2001). Wind data analysis and a case study of wind power generation in Hong Kong. Wind Engineering, 2, 115-123.

Lu, Lin, Yang, Hongxing \& John Burnett. (2002). Investigation on wind power potential on Hong Kong islands-an analysis of wind power and wind turbine characteristics. Renewable Energy, 1, 1-12.

Wang, Changgui, Cui, Rongqiang \& Zhou, Huang,. (2003). Generating electricity technology by new energy. Beijing: China electric power press. Pp. 177-189.

$\mathrm{Xu}$, Weimin, Zhang, Xinglin \& Kong, Xinhong. (2007). Comparison for three methods to calculate Weibull distribution parameters of wind speed. Jiangxi Electric Power, 1, 1-3. 
Zhou, Wei, Yang, Hongxing \& Fang, Zhaozhong. (2006). Wind power potential and characteristic analysis of the Pearl River Delta region. Renewable Energy. 6: 739-753.

Table 1.The monthly Weibull function parameters of Guangzhou

\begin{tabular}{|l|l|l|l|l|}
\hline Month & $k$ & $c$ & $v_{M P}(\mathrm{~m} / \mathrm{s})$ & $v_{\operatorname{MaxE}}(\mathrm{m} / \mathrm{s})$ \\
\hline January & 1.292 & 1.838 & 0.581 & 3.790 \\
\hline February & 1.074 & 1.748 & 0.145 & 4.652 \\
\hline March & 1.280 & 1.727 & 0.527 & 3.601 \\
\hline April & 1.172 & 1.690 & 0.329 & 3.952 \\
\hline May & 1.145 & 1.784 & 0.294 & 4.310 \\
\hline June & 1.125 & 1.879 & 0.266 & 4.660 \\
\hline July & 1.036 & 1.928 & 0.076 & 5.439 \\
\hline August & 1.000 & 1.451 & 0.000 & 4.973 \\
\hline September & 1.000 & 1.391 & 0.000 & 5.595 \\
\hline October & 1.007 & 1.805 & 0.013 & 5.350 \\
\hline November & 1.115 & 1.874 & 0.244 & 4.709 \\
\hline December & 1.252 & 1.826 & 0.507 & 3.915 \\
\hline
\end{tabular}

Table 2. Energy generated by wind turbine FD2.5-300 per month

\begin{tabular}{|l|l|l|ll|}
\hline Month & $\begin{array}{l}\text { Energy generated per month } \\
(\mathrm{kW} \cdot \mathrm{h})\end{array}$ & Month & $\begin{array}{l}\text { Energy generated per month } \\
(\mathrm{kW} \cdot \mathrm{h})\end{array}$ \\
\hline January & 4.743 & July & 11.113 & \\
\hline February & 6.679 & August & 6.965 & \\
\hline March & 3.863 & September & 8.065 & \\
\hline April & 4.719 & October & 10.019 & \\
\hline May & 6.368 & November & 7.890 & \\
\hline June & 7.742 & December & 5.102 & \\
\hline
\end{tabular}

Table 3. The energy generated under different wind turbine hub heights

\begin{tabular}{|l|l|l|}
\hline Heights $(\mathrm{m})$ & Energy generated per year $(\mathrm{kW} \cdot \mathrm{h})$ & Generation cost $(\mathrm{RMB} / \mathrm{kW} \cdot \mathrm{h})$ \\
\hline 41 & 83.195 & 1.322 \\
\hline 80 & 111.041 & 0.991 \\
\hline 120 & 131.314 & 0.838 \\
\hline 160 & 147.368 & 0.746 \\
\hline 200 & 161.382 & 0.680 \\
\hline
\end{tabular}




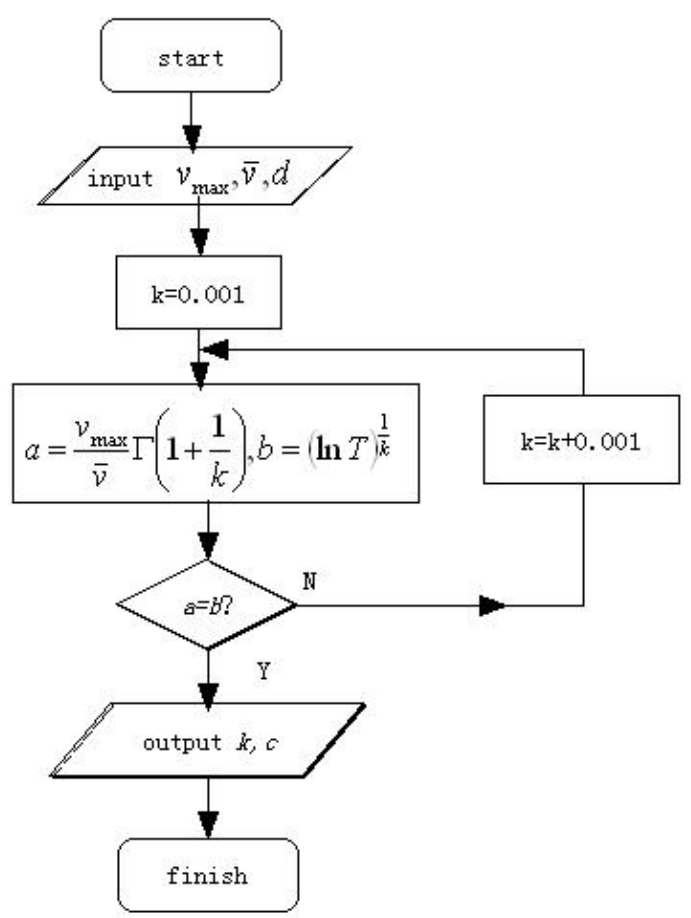

Figure 1. The flow chart of identifying the Weibull parameter $k$ and $c$

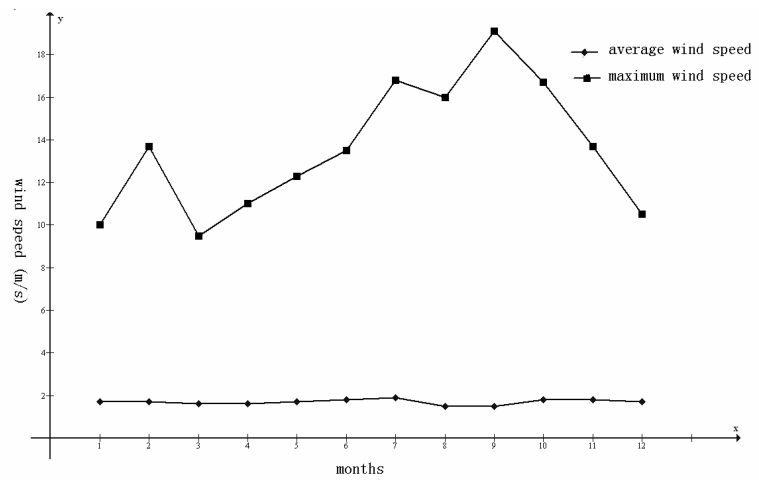

Figure 2. The average wind speed and the maximum wind speed in Guangzhou.

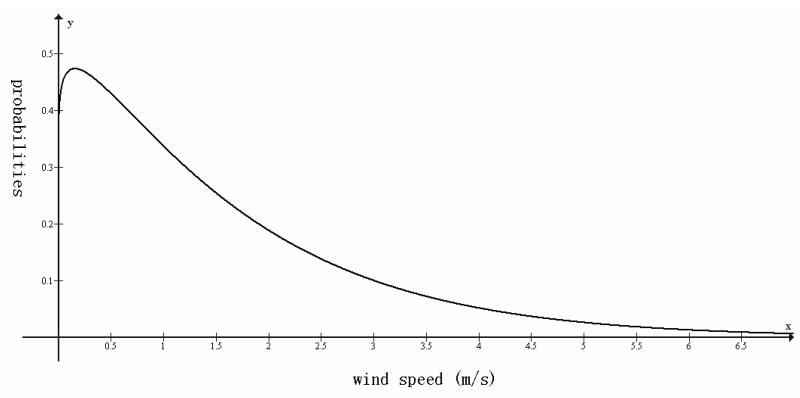

Figure 3. Yearly wind probability density function 


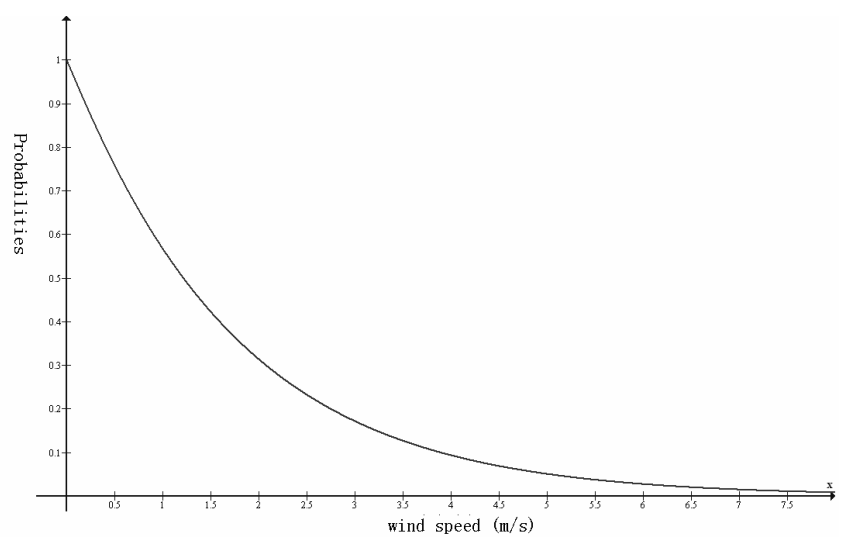

Figure 4. Probabilities of the wind speed exceeding a certain value.

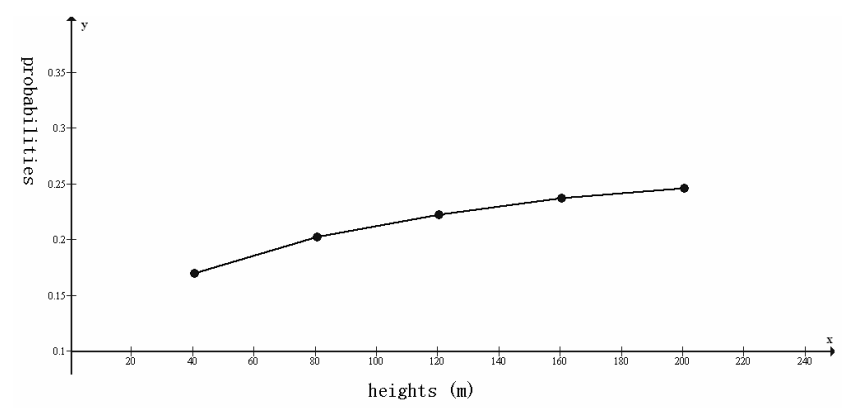

Figure 5. The operating probabilities of wind turbines in Guangzhou at different heights.

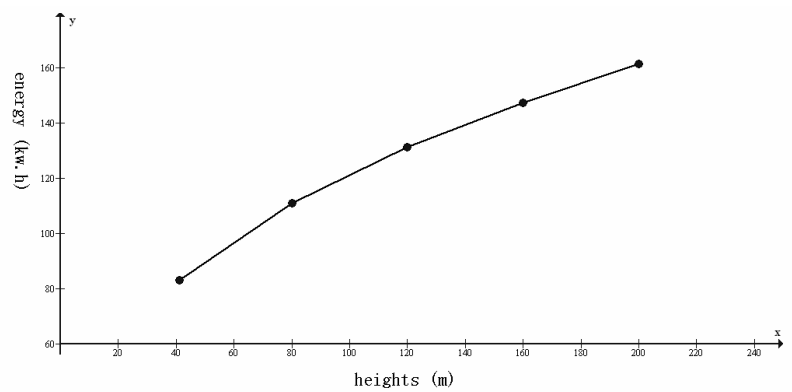

Figure 6. The yearly energy generated by the wind turbines in Guangzhou at different hub heights. 